\title{
JOURNAL OF APPLIED SOCIAL PSYCHOLOGY
}

\section{Gender and Sequelae of Child Versus Adult Onset of Sexual Victimization: Body Mass, Binge Eating, and Promiscuity}

\author{
TERRI D. CONLEY \\ Departments of Women's Studies and \\ Psychology \\ University of Michigan
}

\author{
Megan R. Garza \\ YWCA St. Louis Regional Sexual \\ Assault Center \\ St. Louis, $M O$
}

\begin{abstract}
This research investigated gender differences in and behavioral sequelae of adult vs. childhood sexual victimization among a group of undergraduates in a midwestern city. We administered a survey about sexual experiences, eating habits, and weight to individuals who were first victimized in childhood ( $<$ age 15); were first victimized in adulthood ( $>$ age 18); or had not been sexually victimized. We predicted that those victimized as children would have higher body weight and display more sexual activity than would those victimized as adults. We demonstrated that participants victimized in childhood had significantly higher body mass and weight than did nonvictims or those victimized in adulthood. Men sexually abused as children displayed more promiscuity than did men victimized in adulthood.
\end{abstract}

Sexual victimization occurs in every country in the world (Heise, Pitanguy, \& Germain, 1994). Be it in adulthood or childhood, sexual victimization is often profoundly psychologically disruptive. Victims of sexual crimes frequently exhibit problems with adjustment later in life, such as depression, self-destructive behaviors, anxiety, poor self-esteem, substance abuse, and sexual maladjustment (Browne \& Finkelhor, 1986). Little research is available, however, directly comparing the effects of child victimization to adult victimization, or comparing women's and men's experiences. In the current research, we were interested in gender differences in the victimization experience and whether victimization at distinct life stages would influence impulsive behaviors differently.

\section{Terms and Definitions}

For the purpose of this study, child sexual abuse (CSA) is defined as any unwanted and nonconsensual sexual behavior occurring before the age of 16 years (i.e., $0-15$ years) with a perpetrator who was at least 5 years older than the victim at the time of the abuse (adapted from Maker, Kemmelmeier, \& Peterson, 2001). Adult sexual assault (ASA) is defined as any nonconsensual 


\section{2}

sex act occurring at the age of 18 years or later, regardless of the age difference between survivor and perpetrator (Maker et al., 2001).

Different researchers have defined childhood in different ways. Puberty is another potential way to distinguish between childhood and adult abuse, but the age of puberty is idiosyncratic, making it difficult to determine when each individual is no longer a child (Maker et al., 2001). Moreover, puberty is a long process, with no clear consensus about which markers of puberty should move someone from one age category to the next for the purposes of understanding sexual victimization. Some argue that the meaning of puberty is greater for the perpetrator (who may not be attracted to individuals with a post-pubescent appearance) than it is for the victim (Maker et al., 2001). For these reasons, we choose to rely on Maker et al.'s distinction between CSA and ASA focusing on individuals experiencing abuse at younger than 16 years, or older than 18 years, as distinct groups.

\section{Age of Onset of Sexual Victimization: A Developmental Perspective}

Traditional developmental stage theories suggest that a child's identity is influenced by the interactions he or she has with others during different stages of development. According to these theoretical perspectives, if anything goes wrong at one stage, the child may have difficulty achieving the next stage of development, or the child may develop a pathology distinct to a certain stage (Erikson, 1964; Piaget, 1976). Modern theories of development have moved away from such global stage theories, but developmental psychopathologists maintain that the impact of traumatic experiences on development will vary according to when they happen during the life cycle (Bukowski, 1992). In certain age-specific sensitive periods (i.e., childhood), an individual is more sensitive to the effects of a traumatic event than in other life stages (i.e., adulthood; Bornstein, 1989; Bukowski, 1992; Cicchetti \& Lynch, 1995; Finkelhor \& Kendall-Tackett, 1997).

Empirical research addressing sexual victimization onset has corroborated the idea that traumatic events can cause more harm at some phases of the life cycle than others. Indeed, one of the most important factors associated with symptom expression after CSA is the child's age at the time of the incident or incidents (Green, Ramelli, \& Mizumoto, 2001; Kaplow \& Widom, 2007; Kazdin, 1992; Wolfe \& McGee, 1994). Young victims often suffer more serious consequences to their psychological adjustment (Bukowski, 1992; Haugaard \& Reppucci, 1988); and younger age of onset is positively correlated with greater maladaptive behaviors (Wonderlich et al., 2001), more psychological distress in adulthood (Steel, Sanna, Hammond, Whipple, \& Cross, 2004), and more specific physical and psychological 
symptoms during adulthood compared to those who were victimized later in childhood (Van der Kolk, Perry, \& Herman, 1991). Thus, the sequelae of CSA differ by age of victimization onset among children, but few comparisons have been made between CSA and ASA survivors. Therefore, we do not know whether survivors whose victimization began in childhood differ from survivors who were first victimized as adults.

Following the lead of other researchers who have considered the impact of trauma at critical stages of development (e.g., Kaplow \& Widom, 2007), we utilized the onset of victimization to distinguish between adult and child victims. Repeated victimization of sexual abuse victims is common (Classen, Palesh, \& Aggarwal, 2005); therefore, many childhood victims will also be adult victims. Of course, it is important to consider issues like the extent and severity of abuse, and also to consider those who were abused only as children and not abused as adults, when adopting this approach.

However, in this research, our primary consideration is when the abuse began, be that in childhood or in adulthood. The consideration of the onset of a person's sexual abuse is directly derived from our theoretical perspective, which focuses on certain critical time periods at which traumatic events may occur, and the impact of trauma at those time periods on the responses of the victim. Based on this theoretical perspective, it is the initial abuse in childhood that should be associated with unique reactions to sexual victimization. Thus, subsequent abuse in adulthood should not be associated with a unique pattern of response. That is, the patterns developed as a result of the childhood abuse should still predominate, even if additional traumatic events occur following the initial incidents (see Finkelhor \& Kendall-Tackett, 1997).

\section{Sexual Abuse in Childhood}

Why might CSA be associated with different or more negative psychosocial outcomes than ASA? Current organizational perspectives on development suggest that a child proceeds through a sequence of hierarchical integration and organization of their personal traits (Cicchetti \& Cohen, 1995). That is, each aspect of development builds on the last. Challenges to early developmental integration (e.g., environmental stress, psychological crisis) may compromise an individual's future adaptive abilities (Cicchetti \& Cohen, 1995). Thus, CSA may disrupt the development of this organization, cumulatively limiting one's abilities to respond to the challenges of later developmental stages. In particular, self-regulation, a skill learned in early childhood, may be disrupted by CSA, thus increasing risk of future psychopathology (Briere, 2002; Cicchetti, 1989). Self-regulation is perhaps disrupted 
by traumatic abuse events because the child is controlled by others, just at the point that the child should be learning the skill of controlling his or her own behavior (Briere, 2002; Cicchetti, 1989). Without self-regulation, the survivor may be especially likely to engage in impulsive behaviors (e.g., binge eating, elevated numbers of sexual partners) because self-control skills are underdeveloped.

\section{Adult Sexual Assault}

The impact of sexual victimization on the self is markedly different for ASA survivors. Adults have already passed the major sensitive periods of development (Bukowski, 1992). Therefore, adult traumatic experiences, though still harmful, may have a less global and consequential impact on survivors' lives than childhood victimization. Still, adults who have had normal development may, of course, be shaken by a traumatic sexual experience. Presuming they have developed a healthy self-concept and normal sexual development, Bukowski proposed that the challenge for ASA survivors is the integration of the meaning of the event into one's already existing beliefs about the world. That is, the traumatic violent event greatly reduces the ASA victims' sense of control over their life and the world around them. They are forced to reckon with the fact that they cannot prevent traumatic events from occurring. Thus, in contrast to CSA victims, who are inhibited from learning self-control, ASA victims who likely have already learned self-control may try to control their own behaviors very carefully (e.g., by restricting their eating behaviors or sexual behaviors; Bukowski, 1992). Symptom expressions as a result of ASA can often be construed as attempts to restore oneself to prior feelings of safety and self-efficacy (Bukowski, 1992).

\section{Effects of Onset of Sexual Victimization on Impulsivity and Inhibition}

Because adult versus childhood victimization may differentially affect self-regulation (inhibiting self-control in childhood victims and intensifying self-control efforts among adults), survivors of CSA may differ from adult survivors in their levels of impulsivity. Impulsivity, or lack of inhibition, is defined as acting without thinking, making quick decisions, and demonstrating a lack of foresight in making decisions (Patton, Stanford, \& Barratt, 1995). In one study (Wonderlich et al., 2001), 97 women who were either sexually abused in childhood, adulthood, or who were nonvictims were compared in terms of their impulsivity. Survivors of CSA engaged in higher levels 
of impulsive behaviors than did nonvictims (Wonderlich et al., 2001). By contrast, adulthood victimization has been found to be associated with a lack of impulsivity and higher levels of inhibition relative to nonvictims. Researchers have observed that ASA survivors exhibit controlled avoidance and restrictive behaviors related to eating, sexual activity, and social activity, relative to nonvictims (Acierno et al., 2002; Atkeson, Calhoun, Resick, \& Ellis, 1982; Becker, Skinner, Abel, \& Cichon, 1986; Calhoun, Atkeson, \& Resick, 1982; Nadelson, Notman, Jackson, \& Gornick, 1982; Veronen \& Kilpatrick, 1983).

\section{Impulsivity and Eating Behaviors}

One impulsive behavior that research has found to be different for those sexually victimized in adulthood versus childhood (when these groups are examined in separate studies) is eating behaviors. CSA is positively related to disturbances in eating. Smolak and Murnen (2002) conducted a metaanalysis of 53 studies that examined the relationship between CSA and eating disorders, and concluded that a small but significant relationship exists. Gustafson and Sarwer (2004) found a relationship between CSA, eating disorders, and impulsivity. They found that CSA is especially likely to be associated with bulimia (an eating disorder related to impulsive tendencies), as opposed to anorexia (an eating disorder related to restrictive tendencies). By contrast, research on the long-term effects of rape has shown that weight loss is common for survivors of rape (Schechter, Schwartz, \& Greenfield, 1987), suggesting that ASA survivors may be restricting their food intake.

Most studies of ASA and CSA include predominantly female participants, so examining gender effects is difficult. However, we do know that women display more emotional eating than do men (e.g., Tanofsky, Wilfley, Spurrell, \& Welch, 1997). The consumption of food may be a more acceptable or desirable way for women (relative to men) to manage negative emotions, such as those associated with sexual victimization. Likewise, because most previous research has not compared survivors of adult-onset victimization to survivors of child-onset victimization, we cannot determine whether age of onset of sexual victimization has different effects on eating behaviors for child or adult survivors.

Another gap in the extant victimization literature is that nonclinical weight problems are frequently overlooked as an area of study. Little emphasis has been placed on possible nonclinical (but still detrimental) maladaptive eating behaviors. We consider nonclinical maladaptive behaviors in the current research. 


\section{Impulsivity and Sexual Behaviors}

A second impulsive behavior that may be affected by sexual abuse is sexual activity, particularly sexual encounters with multiple partners. CSA survivors frequently develop maladaptive sexual patterns, which researchers suspect are a result of their victimization (Browne \& Finkelhor, 1986). A meta-analysis of 37 studies found a significant relationship between CSA and promiscuity, with a .59 unweighted and .29 weighted effect size (Paolucci, Genuis, \& Violato, 2001). These results indicate a significant relationship between sexual victimization and promiscuous behaviors among childhood victims.

By contrast, ASA survivors exhibit very different sexual behavior patterns. Following a rape or sexual assault, it is common for ASA survivors to experience disturbances in sexual functioning that include fear of sex, arousal dysfunction, and decreased libido (Becker et al., 1986; Burgess \& Holstrom, 1985; Ellis, Atkeson, \& Calhoun, 1981). Thus, research has indicated that ASA survivors commonly experience a reduction in sexual activity levels, whereas CSA survivors appear to participate in high levels of sexual behavior following their abuse, consistent with theories of impulsivity and restriction. Once again, gender comparisons have rarely been made because of the higher prevalence of sexual victimization experiences among women. However, promiscuity is considered more acceptable for men than for women (Wiederman, 1997). Therefore, engaging in heightened sexual activity might be a more acceptable way for men to cope with the negative emotions associated with sexual victimization. For this reason, we suggest that men may be more likely than women to demonstrate the impact of sexual victimization through sexual activity.

\section{Comparisons of Child-Onset and Adult-Onset Victimization Experiences}

Most previous research has examined the impact of either CSA or ASA on survivors separately. Alternately, studies have combined child and adult survivors into one broad victimization category. A limitation of the existing literature is that it has seldom directly compared the long-term effects of CSA to ASA (Waller, 1991; Wonderlich et al., 2001).

In the current research, we examined survivors who were victimized first as children separately from those who were victimized first as adults. This allowed us to assess whether abuse beginning in childhood has a different impact on the impulsive behaviors of promiscuity and unregulated eating. Notably, to provide discriminant validity, we predicted that victims (irrespective of victimization onset) and nonvictims would not differ on these measures. 


\section{Gender Differences in Reaction to Victimization}

We predict that, in general, CSA will be associated with more impulsive behaviors; and ASA will be associated with more restrictive behaviors. However, we also suggest that specific differences in the socialization of women and men may lead to different outcomes in response to victimization. Women and men may express their impulsivity in gender-appropriate ways. Excessive eating may be more acceptable for women than for men (e.g., Feingold \& Mazzella, 1998), but promiscuous sexual behaviors may be more appropriate for men than for women (e.g., Wiederman, 1997). The long-term effects of sexual abuse, then, may be filtered through the individual's gender role. That is, women may perceive that it is more acceptable to overeat than to engage in sexual activities with many partners, whereas men may perceive the converse. Therefore, the effects of victimization onset on impulsive activities may be heightened for women on the dimension of eating and for men on the dimension of sexual behavior.

\section{Summary and Hypotheses}

In sum, contemporary research and theory strongly suggest that the effects of sexual victimization differ, depending on the onset of the victimization. However, research that directly compares these two groups is scarce. The study presented here compared women and men in three groups: those who were first sexually victimized in adulthood, those who were victimized first when they were children, and a nonvictimized control group. We are interested in whether age of onset of victimization experiences affects women and men differently in the outcomes of adult weight, binge-eating behaviors, and promiscuity. We are particularly interested in these factors as they operate through the mechanisms of impulsivity and inhibition.

Although women's responses to victimization have been studied more thoroughly than have men's responses, we predict that women and men will respond differently to childhood versus adult victimization experiences. That is, we predict that both women and men will show more impulsive behaviors (e.g., heightened eating disturbances, sexual behaviors) as a response to victimization commencing in childhood. However, the expression of impulsive behaviors may also be associated with proscribed gender roles, with men more likely to express their symptoms in the context of sexuality, and women more likely to express their symptoms in the context of eating behaviors. 


\section{Method}

\section{Participants}

Participants ( $N=147$; 118 women, 29 men) were volunteers for a study on "traumatic sexual experiences" at an urban university in the Midwest. Students were alerted via paper advertisements on research participation billboards that they could volunteer to participate if they had experienced sexual victimization prior to age 16 , after age 18 , or if they had never been victimized. The sample was $80 \%$ female, and the mean age was 26.3 years. Ethnically, the participants were Caucasian (53\%), African American $(36 \%)$, Hispanic (2\%), Asian American (5\%), biracial or multiracial $(3 \%)$, or other $(1 \%)$. No volunteers refused to participate when they came to the research room; all completed the study.

\section{Measures}

Sexual Abuse Exposure Questionnaire (SAEQ). The SAEQ is a 10-item self-report questionnaire that assesses childhood and adult sexual victimization (Ryan, Rodriguez, Rowan, \& Foy, 1992). The self-report measure asks questions about 10 sexual experiences, ranging from genital exposure to intercourse. Participants are asked to indicate if the events occurred "when you did not want them to occur," ensuring that the participant is addressing nonconsensual events. A sample item is "Did a person ever manually or orally stimulate your genital area?" For each item, participants responded Yes, No, or Not sure.

Child victimization was determined if a participant responded Yes to any items addressing events experienced before the age of 16, with a person 5 or more years older. Adult victimization was determined if a participant responded Yes to any of the sexual assault items (but did not respond Yes for the childhood sexual abuse items) indicating unwanted experiences after age 18. Thus, this questionnaire distinguished between participants for whom victimization started in childhood and those for whom victimization started in adulthood. Those victimized at ages 16 and 17 were omitted from the research because of variation in the literature concerning classification of 16- and 17-year-olds firmly as children/adolescents or adults (i.e., their age would classify them as children/adolescents, but their level of sexual development could also classify them as adults).

In addition, participants who responded $N o$ to all items comprised the nonvictimized group. Participants also reported on (a) frequency of the victimization; (b) duration of the victimization; (c) degree of violence; 
(d) degree of threatened violence; (e) closeness of the relationship with the perpetrator; and (f) degree of social support following the sexual victimization. Trauma-related construct validity has been demonstrated for the modified SAEQ (Ryan et al., 1992).

Sexual Activity/Promiscuity Index. The Sexual Activity/Promiscuity Index is a brief survey comprised of questions about the number of oral sex partners and vaginal sex partners one has had in the past month, year, and lifetime to determine each participant's level of sexual activity. For our purposes, we focus on two items, concerning the number of lifetime oral sex partners and vaginal sex partners. We averaged these items to form a scale with a reliability of .62 .

Barratt Impulsiveness Scale (BIS-11). The BIS-11 (Patton et al., 1995) is a 30-item self-report questionnaire that assesses the frequency of attentional, motor, and non-planning impulsive behaviors. Participants responded to the items on a 6-point scale ranging from 1 (never) to 6 (always). Higher numbers indicate more impulsiveness. All 30 items were averaged to create a scale that yielded a reliability alpha of .81 in the present sample.

Binge Eating Scale (BES). The BES assesses binge-eating behaviors using a 16-item self-report questionnaire (Gormally, Black, Daston, \& Rardin, 1982). The scale includes eight descriptions of feelings and cognitions and eight behavioral manifestations of binge eating. In the scale, participants read groups of statements related to binge eating and indicated which one applied to them the most. There were four descriptions that could be chosen for each of the 16 scale items. Response items least related to binge eating are coded as 1 , while those most associated with binge eating are coded as 4, such that higher numbers indicate greater amounts of binge eating. Items were averaged to create a composite participant score. The reliability was .93 .

Body mass index (BMI). The BMI is a measurement of a person's body mass. BMI is calculated by taking the participant's height in inches, divided by her or his total body weight. A BMI calculator on the Centers for Disease Control website was used to ensure accurate results. Measures on the BMI are used to classify individuals as being underweight, normal weight, overweight, obese, or morbidly obese.

\section{Procedure}

Participants arrived at the study site and read and signed a detailed consent form. Because of the sensitive nature of the questionnaire items, the Institutional Review Board (IRB) required that participants complete the questionnaire alone. Therefore, upon his or her arrival at the research room, 
each participant was seated and was given instructions for completing the survey packet. The participants were given a scale to weigh themselves and were asked to record their weights on the demographic sheet. They were instructed to place their survey packets inside a large envelope, seal it, and return the envelope to the researcher when completed.

\section{Results}

First, we conducted descriptive analyses to determine the childhood-onset and adult-onset victimization groups. Next, to determine differences in the victimization experiences of child-onset and adult-onset survivors, we conducted MANOVAs comparing the childhood-onset and adult-onset victimization groups. Then, we analyzed data addressing BMI, promiscuity, and impulsivity using a series of 2 (Gender) $\times 3$ (Victimization Category: sexual victimization began during childhood, sexual victimization began after age 18, or nonvictimized controls) ANCOVAs.

As necessary, we statistically controlled for differences between the adultonset victimization and child-onset victimization groups in their victimization experiences (i.e., frequency of victimization, duration of victimization, degree of violence, degree of threatened violence, closeness of relationship with perpetrator, and degree of social support following the sexual victimization), as well as age and ethnicity. We also determined the association between the variables via correlations. Finally, we compared victims (irrespective of the onset of their victimization) to nonvictims.

\section{Sexual Assault Experiences}

Based on their responses to the SAEQ (Ryan et al., 1992), 75 participants were classified as having experienced child-onset victimization (51\%), 39 were classified as having experienced adult-onset victimization (27\%), and 33 were classified as having experienced no victimization $(22 \%)$. We suspect that the percentage of participants who had experienced abuse was so high because we specifically recruited for a study on traumatic sexual experiences. Those who had experienced sexual trauma were probably more likely to find the topic of interest and, hence, were more likely to volunteer.

Not incidentally, this recruitment method allowed us to informally oversample those who had experienced victimization. We needed a large enough sample of victimized participants to make comparisons between those who had experienced childhood-onset versus adult-onset victimization. To study sexual victimization in different subgroups (i.e., victimization onset 
and gender), it was necessary to include a large sample of sexually victimized people. Participants who were victimized in both childhood and adulthood, because their victimization began during childhood, were counted as part of the child-onset victimization group. Notably, analyses were also conducted by further breaking down the child victimization group into two groups: those who had been victimized only in childhood, and those who had been victimized in both childhood and adulthood. The responses of the childhoodonly victimization $(n=24)$ group overlapped substantially with the responses of participants who had been victimized both in childhood and adulthood $(n=55)$. There were no significant differences between these groups.

This finding is consistent with the hypotheses of stage-development theories. That is, the fact that the initial abuse happened during a sensitive stage of development, according to stage-development theories, should be a more important predictor of impulsive behaviors than the duration of traumatic experiences. ${ }^{1}$ For these reasons, the two groups were merged in the analyses presented here.

\section{Victimization Onset, Gender, and Characteristics of the Victimization Experience}

We conducted a 2 (Gender) $\times 2$ (Victimization Type) MANOVA to determine if participants in any of these groups differed in terms of their victimization experiences or demographic variables. Participants whose victimization began in childhood had more severe experiences than did those whose victimization began in adulthood, as evidenced by a main effect of victimization type, $F(7,104)=3.58, p<.002$. Specifically, childhoodonset participants reported a longer duration of victimization, $t(91)=3.92$, $p<.0005$; greater frequency of abusive incidents, $t(91)=2.19, p<.018$; a higher degree of experienced physical violence, $t(91)=2.14, p<.035$; and less social support received after the victimization, $t(91)=3.05, p<.003$, than did participants in the adult-onset victimization group.

The two groups did not differ on the degree of closeness of the perpetrator or the degree to which they were threatened with violence. They also showed no differences in age or likelihood of belonging to a particular ethnic group. By contrast, the MANOVA indicates that women and men did not differ on any of these factors, $F(7,106)=0.57, n s$. No interactions between victimiza-

${ }^{1}$ This perspective does not, of course, discount the possibility that more or longer durations of abuse experiences may have more negative outcomes in many or most domains. It only indicates that the timing of the abuse is associated with greater or lesser disruption of the particular dimension of interest: impulsivity. 
tion type and gender emerged. Because differences between groups emerged on some dimensions, we included those variables as covariates in subsequent analyses.

\section{Gender, Impulsivity, and Victimization Category}

We predicted that childhood-onset victims would report higher levels of impulsivity than would adult-onset victims or nonvictimized controls. However, we found no evidence that victimization-onset groups or controls differed in their level of impulsivity. A 3 (Victimization Category: childhood onset, adult onset, or control) $\times 2$ (Gender) ANCOVA reveals no relationship between victimization type and impulsivity, $F(2,147)=0.25$, ns. No significant covariates emerged.

\section{Gender, BMI, and Victimization Category}

We predicted that victims of childhood-onset victimization would report higher levels of impulsivity than would adult-onset victims or nonvictimized controls. A 3 (Victimization Category: childhood onset, adult onset, or control) $\times 2$ (Gender) ANCOVA reveals a significant main effect of victimization category, $F(2,140)=4.70, p=.01$. As shown in Table 1, participants whose victimization began in childhood had a higher BMI than did those whose

\section{Table 1}

Group Means for BMI (and Classification of BMI scores) and Binge Eating Among Childhood Victimized, Adulthood Victimized, and Nonvictimized Individuals

\begin{tabular}{|c|c|c|c|c|c|c|}
\hline \multirow{2}{*}{$\begin{array}{l}\text { Dependent } \\
\text { variable }\end{array}$} & \multicolumn{2}{|c|}{$\begin{array}{l}\text { Child victims } \\
\quad(n=75)\end{array}$} & \multicolumn{2}{|c|}{$\begin{array}{l}\text { Adult victims } \\
\quad(n=39)\end{array}$} & \multicolumn{2}{|c|}{$\begin{array}{l}\text { Nonvictims } \\
\quad(n=33)\end{array}$} \\
\hline & $M$ & $S D$ & $M$ & $S D$ & $M$ & $S D$ \\
\hline BMI score & 29.37 & 8.42 & $23.00^{*}$ & 4.01 & $25.75^{*}$ & 6.35 \\
\hline Classification & \multicolumn{2}{|c|}{ Overweight } & \multicolumn{2}{|c|}{ Normal } & \multicolumn{2}{|c|}{ Overweight } \\
\hline Binge eating & 1.88 & 0.58 & $1.67 *$ & 0.63 & $1.64 *$ & 0.50 \\
\hline
\end{tabular}

Note. $\mathrm{BMI}=$ body mass index (higher numbers indicate greater body mass). The binge-eating items were rated on a 4-point scale. Higher numbers indicate greater amounts of binge eating. Means with asterisks do not differ from one another. 
victimization began in adulthood, or non-abused controls. Tukey's post hoc tests comparing child- and adult-onset survivors reveals a significant difference between these groups, as shown in Table 1. As hypothesized, ASA survivors had a lower BMI (falling in the normal weight range; see Table 1) than did those who were victimized in childhood (whose BMIs, on average, fell in the obese range) with nonvictim BMIs (falling in the overweight range) between those of adult and child survivors. Only age emerged as a significant covariate in this analysis. No interaction with gender was found.

Given the small number of male participants, we were curious as to whether the predicted result could be found for males separately. Therefore, as a final analysis of BMI, to ascertain whether men were displaying the predicted effects, we conducted a one-way ANOVA of men only. The predicted effects were demonstrated among men, $F(2,28)=3.55, p=.044$. Tukey's post hoc tests demonstrate that men who had been sexually victimized in childhood had higher BMIs $(M=26.81, S D=4.83)$ than did those who were sexually victimized as adults $(M=22.39, S D=3.05)$, but did not differ from men who were not victimized $(M=27.78, S D=4.77)$.

\section{Gender, Binge-Eating Behaviors, and Victimization Category}

We predicted that participants who experienced childhood-onset victimization would display more binge eating than would adult-onset victims or nonvictimized controls. A 3 (Victimization Category: childhood onset, adult onset, or control $) \times 2$ (Gender) ANCOVA reveals a significant main effect of victimization category, $F(2,139)=4.74, p=.01$ (see Table 1). Participants who experienced victimization commencing in childhood displayed significantly more binge-eating behavior than did participants from the other two victimization categories. Only age emerged as a significant covariate. There was no main effect of gender. This finding is consistent with our hypothesis that those who were victimized in childhood should display more impulsive (and fewer restrictive) behaviors than those who were victimized as adults. Moreover, no interaction with gender was found.

Because of the small number of male participants, we were curious as to whether the predicted result could be found for males separately. To determine whether men were displaying the predicted effects, we conducted a one-way ANOVA on men only. The predicted effects were demonstrated among men, $F(2,28)=6.72, p=.004$. Tukey's post hoc tests demonstrate that men who had been sexually victimized in childhood had higher levels of binge eating $(M=1.79, S D=.46)$ than did those who were sexually victimized as adults $(M=1.25, S D=.20)$, or men who were not victimized $(M=1.37, S D=.28)$. Because our sample of men was small, these significant results suggest that these are large and important effects. 
Table 2

Group Means by Gender on Promiscuity Scores Among Childhood Victimized, Adult Victimized, and Nonvictimized Individuals

\begin{tabular}{lrrrrr}
\hline & \multicolumn{2}{c}{ Men } & & \multicolumn{2}{c}{ Women } \\
\cline { 2 - 3 } \cline { 5 - 6 } Group & \multicolumn{1}{c}{$M$} & $S D$ & & $M$ & $S D$ \\
\hline Childhood-onset victims & 29.83 & 14.01 & & $5.73^{*}$ & 5.80 \\
Adult-onset victims & 5.63 & 8.16 & & $6.93^{*}$ & 9.24 \\
Controls & 17.38 & 17.80 & & $4.09^{*}$ & 4.83 \\
\hline
\end{tabular}

Note. Promiscuity scales are a sum of the lifetime total number of oral and vaginal partners. Therefore, higher numbers indicate more partners. Means with asterisks do not differ from one another.

\section{Gender, Promiscuity and Victimization Category}

We again conducted a 3 (Victimization Category: childhood onset, adult onset, or control) $\times 2$ (Gender) ANCOVA. We predicted that victims of childhood-onset sexual victimization would report higher levels of promiscuity than would adult-onset victims or nonvictims. Whether or not this finding was supported was equivocal. A main effect emerged for victimization type, $F(2,140)=3.33, p<.039$. However, in Tukey's post hoc analyses, none of the individual means differed significantly from one another, although the means were in the predicted direction.

We further predicted that male victims would show the effects of traumatic experiences more strongly in their sexual behaviors than would female victims. An interaction emerged between sex and victimization onset, $F(2,140)=6.55$, $p=.002$. The predicted effect was shown for men: Tukey's post hoc tests reveal that men who were victimized in childhood had higher numbers of partners than did those who were victimized in adulthood or nonvictimized controls. That is, men who were victimized in childhood displayed more impulsive behaviors (by being more sexually active) than did adult-onset survivors or controls. Among women, no differences emerged between childhood-onset and adult-onset groups or the controls. The exact configuration of means is displayed in Table 2. No significant covariates emerged.

\section{Correlations Among Impulsivity, Binge Eating, BMI, and Promiscuity}

Next, we conducted correlations among the independent variables, controlling for gender. There was a significant association between binge-eating 
Table 3

Correlations Among Study Variables

\begin{tabular}{lccc}
\hline Variable & 1 & 2 & 3 \\
\hline 1. Impulsivity & - & & \\
2. Promiscuity & .08 & - & \\
3. Binge eating & $.35^{* *}$ & $.19^{*}$ & - \\
4. Body mass index & -.08 & $.24 * *$ & $.18^{*}$ \\
\hline${ }^{*} p<.05 .{ }^{* *} p<.01$. & & &
\end{tabular}

behaviors and impulsivity. Moreover, binge-eating behaviors were significantly correlated with BMI. More surprisingly, binge eating and BMI were both correlated with promiscuity (see Table 3 ). Although the victimization groups did not show differences in their impulsivity scores, the fact that impulsivity was correlated with binge eating suggests that impulsivity may still be a worthy subject of research for explaining the relationships between victimization and maladaptive eating behaviors. Moreover, the correlation of promiscuity with BMI and binge eating suggests that these behaviors could emanate from a more general psychological predisposition. However, impulsivity and promiscuity were uncorrelated.

Perhaps the predicted association between sexual victimization and impulsivity — and, in turn, impulsivity, binge eating, and promiscuity - might successfully be modeled in a different sample. In particular, we might demonstrate these effects among samples with more statistical power or among clinical samples of persons with bulimia or clinical sexual problems.

\section{Comparisons of Survivors to Nonvictims}

To provide convergent evidence for the importance of considering victimization onset, we also conducted a 2 (Victim Group: victims vs. nonvictims) $\times 2$ (Gender) MANOVA comparing survivors (irrespective of the onset of the victimization; i.e., both the child-onset and adult-onset survivors together in one group) to nonvictims. Interestingly, there were no significant differences between survivors and nonvictims on any of the individual measures. The overall MANOVA for victim group was nonsignificant, $F(4,132)=0.60, n s$, as was the interaction between victim group and sex, $F(4$, $132)=0.56, n s$. This null finding - contrasted with the significant findings described earlier - further elucidates the importance of victimization onset for psychosocial outcomes that are associated with sexual violence. 


\section{Discussion}

This study examined the potentially far-reaching long-term effects of adult-onset and child-onset sexual victimization. We examined gender differences in the experience of sexual abuse, and compared the responses of those who were victimized in childhood (age 15 and younger) to those who were victimized in adulthood (age 18 and older) in the areas of impulsivity, body mass, binge eating, and promiscuity. Based on research and theory addressing sensitive periods of development, we hypothesized that individuals who first experienced victimization in childhood would show evidence of more impulsive behaviors (i.e., disordered eating, promiscuity) than would those whose victimization began in adulthood, or nonvictims. We also expected reactions to victimization to be filtered through an individual's gender role, with men showing greater reactions in the domain of promiscuity, and women showing greater reactions in the domain of eating.

Consistent with the hypotheses, childhood-onset victims had higher BMIs than did those who were victimized in adulthood, with nonvictim BMIs falling between those of adult and child survivors. BMIs for child-onset survivors fell on the border between the overweight and obese ranges of body mass, whereas BMIs for adult-onset survivors fell in the normal range. Similar patterns were displayed for binge-eating behaviors. In addition, consistent with our analysis of gender roles and victimization, men who were victimized in childhood had higher numbers of sexual partners than did nonvictimized men; whereas men who were victimized in adulthood had the lowest number of sexual partners.

These results are consistent with prior research indicating that younger age of onset of victimization is positively associated with greater maladaptive behaviors among CSA survivors (Wonderlich et al., 2001). The current research expands the findings to comparisons between survivors of CSA and ASA. We also provide suggestive evidence that men and women may express their impulsivity in gender-appropriate ways. As a response to sexual victimization, excessive eating may be equally acceptable for women and men, but promiscuous sexual behaviors may be perceived as more appropriate for men than for women. The long-term effects of sexual abuse, then, may be filtered through the individual's gender role. That is, women may perceive that it is more acceptable to overeat than to engage in sexual activities with many partners.

Alternately, we could be observing a reporting bias. That is, perhaps women and men engage in promiscuous behaviors equally, but men may be exaggerating the number of sexual encounters they have had; whereas women may be downplaying their number of sexual encounters (Wiederman, 1997). 
Notably, such a reporting bias would also be consistent with proscribed gender roles.

The most perplexing finding is that although there were associations between victimization category and impulsive eating behaviors (for women and men) and sexual behaviors (for men), no differences emerged on our measure of impulsivity. We suspect that the null findings regarding impulsivity may be a function of the impulsivity measure we used. That is, we believe that this measure may be insufficiently sensitive to the types of health behaviors our research addressed. Future research should incorporate measures of impulsivity that are more directly related to sexuality or eating-related impulses. For example, the Urgency, Premeditation, Perseverance, and Sensation-Seeking (UPPS) Impulsivity Scale (Whiteside \& Lynam, 2001) has been used effectively to assess problematic sexual behaviors and disordered eating behaviors, in addition to a variety of other psychopathologies.

Although these findings are suggestive of a causal link between onset of abuse and specific types of maladaptive behaviors, alternative explanations are certainly possible. Perhaps most important, participants who were abused in childhood may have been subjected to other forms of abuse (i.e., physical, psychological, or emotional abuse) that contributed to their more impulsive behaviors. That is, childhood sexual victimization may be associated with other individual-level and environment-based risk factors, including parental psychopathology, domestic violence, and neglect. Differences between groups could be a result of other traumatic experiences, instead of the sexual experiences per se. An in-depth examination of the impact of other traumatic experiences on children and adults would be productive.

\section{Limitations and Future Directions}

\section{Sampling Issues}

The participants were a convenience sample of predominantly White, American college students who responded to a questionnaire on traumatic sexual experiences. Therefore, we can only tentatively draw conclusions about the application of these findings to other groups. It would be useful to replicate these results in a representative sample of the U.S. or an international sample to determine if these findings are generalizable. In addition, we acknowledge that this is a small sample, especially the sample of men. However, the fact that we found significant differences between women and men on the promiscuity dimensions, even with such a small sample, suggests that the gender effects in this domain may be particularly prominent. 


\section{Survivor Classification}

Classifying adult and child survivors proved to be problematic in this sample. Because of the differing information in the literature, it was difficult to find a clear age cutoff for childhood. As a result, we did not consider the experiences of survivors whose abuse began at age 16 or 17. Future researchers may want to consider victimization during this period of childhood separately, or to use different markers for childhood and adulthood.

\section{Depression}

Including measures of depression should be a top priority for future researchers. Depression may contribute to fluctuations in weight, and depression may also be related to victimization, thus creating the possibility that depressive symptoms may predict participants' body-mass scores. Depression could be contributing to differences in weight and body mass for sexually victimized individuals, independent of impulsive behaviors. One possibility is that the depression associated with victimization causes inactivity or overeating, which could lead to higher weight. However, the different outcomes for adult-onset versus childhood-onset survivors would still need to be explained.

\section{Politics of Promiscuity}

We have defined promiscuity as relative amounts of sexual activity for the purposes of this paper. This approach is consistent with the underlying assumption of some previous research on CSA survivors that more sexual activity is evidence of maladaption, as well as messages concerning the prevention of sexually transmitted infections. However, we acknowledge that it is possible that men who have experienced sexual abuse can sexually express themselves in a freer way than other people, and that their higher levels of sexual activity might not be negative. In other words, this group of men may have found a way to channel the negative experience of sexual abuse in a positive sexual direction. Therefore, the negatively valenced term promiscuity and the assumption that greater amounts of partnered sexual activity are more negative may need to be re-examined in future research.

\section{Conclusion}

As previously suggested by developmental theorists, the results of this study demonstrate that child survivors are not the same as adult survivors, 
suggesting that more research and treatments should be devoted to victimization at different ages. In doing so, the research also provides support for theories suggesting that the impact of traumatic life events will be different if they occur in sensitive periods of development. Finally, given the different outcomes for women and men, the current findings suggest the need to consider gender differences in response to sexual victimization, especially with regard to future sexual behaviors.

\section{References}

Acierno, R., Brady, K., Gray, M., Kilpatrick, D. G., Resnick, H., \& Best, C. L. (2002). Psychopathology following interpersonal violence: A comparison of risk factors in older and younger adults. Journal of Clinical Geropsychology, 8, 13-23.

Atkeson, B., Calhoun, K., Resick, P., \& Ellis, E. (1982). Victims of rape: Repeated assessment of depressive symptoms. Journal of Consulting and Clinical Psychology, 50, 96-102.

Becker, J., Skinner, L., Abel, G., \& Cichon, J. (1986). Level of post-assault sexual functioning in rape and incest victims. Archives of Sexual Behavior, $15,37-49$.

Bornstein, M. H. (1989). Sensitive periods in development: Structural characteristics and causal interpretations. Psychological Bulletin, 99, 66-77.

Briere, J. (2002). Treating adult survivors of severe childhood abuse and neglect: Further development of an integrative model. In J. E. B. Myers, L. Berliner, J. Briere, C. T. Hendrix, T. Reid, \& C. Jenny (Eds.), The APSAC handbook on child maltreatment $\left(2^{\text {nd }}\right.$ ed., pp. 1-26). Newbury Park, CA: Sage.

Browne, A., \& Finkelhor, D. (1986). Impact of child sexual abuse: A review of the research. Psychological Bulletin, 99, 66-77.

Bukowski, W. M. (1992). Sexual abuse and maladjustment considered from the perspective of normal developmental processes. In W. O'Donohue \& J. H. Geer (Eds.), The sexual abuse of children: Vol. 1. Clinical issues (pp. 261-282). Hillsdale, NJ: Lawrence Erlbaum.

Burgess, A. W., \& Holstrom, L. L. (1985). Rape trauma syndrome and post traumatic stress response. In A. W. Burgess (Ed.), Rape and sexual assault (pp. 46-60). New York: Garland.

Calhoun, K. S., Atkeson, B. M., \& Resick, P. A. (1982). A longitudinal examination of fear reactions in victims of rape. Journal of Counseling Psychology, 29, 655-661. 
Cicchetti, D. (1989). How research on child maltreatment has informed the study of child development. In D. Cicchetti \& V. Carlson (Eds.), Child maltreatment: Theory and research on the causes and consequences of child abuse and neglect (pp. 377-431). New York: Cambridge University Press.

Cicchetti, D., \& Cohen, D. J. (1995). Perspectives on developmental psychology. In D. Cicchetti \& D. J. Cohen (Eds.), Developmental psychopathology: Vol. 1. Theory and methods (pp. 3-22). New York: John Wiley \& Sons.

Cicchetti, D., \& Lynch, M. (1995). Failures in the expectable environment and their impact on individual development: The case of child maltreatment. In D. Cicchetti, D. J. Cohen, D. Cicchetti, \& D. J. Cohen (Eds.), Developmental psychopathology: Vol. 2. Risk, disorder, and adaptation (pp. 32-71). Oxford, UK: John Wiley \& Sons.

Classen, C. C., Palesh, O. G., \& Aggarwal, R. (2005). Sexual revictimization: A review of the empirical literature. Trauma, Violence, and Abuse, 6, $103-129$.

Ellis, E., Atkeson, B., \& Calhoun, K. (1981). An assessment of long-term reaction to rape. Journal of Abnormal Psychology, 90, 263-266.

Erikson, E. (1964). Childhood and society. New York: Norton.

Feingold, A., \& Mazzella, R. (1998). Gender differences in body image are increasing. Psychological Science, 9, 190-195.

Finkelhor, D., \& Kendall-Tackett, K. (1997). A developmental perspective on the childhood impact of crime, abuse, and violent victimization. In D. Cicchetti \& S. L. Toth (Eds.), Developmental perspectives on trauma: Theory, research, and intervention (pp. 1-32). Rochester, NY: University of Rochester Press.

Gormally, J., Black, S., Daston, S., \& Rardin., D. (1982). The assessment of binge eating severity among obese persons. Addictive Behaviors, 7, $47-55$.

Green, T. M., Ramelli, A., \& Mizumoto, M. (2001). Patterns among sexual assault victims seeking treatment services. Journal of Child Sexual Abuse, 10, 89-108.

Gustafson, T. B., \& Sarwer, D. B. (2004). Childhood sexual abuse and obesity. Obesity Reviews, 5, 129-135.

Haugaard, J. J., \& Reppucci, N. D. (1988). The sexual abuse of children: A comprehensive guide to current knowledge and intervention strategies. San Francisco: Jossey-Bass.

Heise, L. L., Pitanguy, J., \& Germain, A. (1994). Violence against women: The hidden health burden. Washington, DC: World Bank.

Kaplow, J. B., \& Widom, C. P. (2007). Age of onset of child maltreatment predicts long-term mental health outcomes. Journal of Abnormal Psychology, 116, 176-187. 
Kazdin, A. (1992). Child and adolescent dysfunction and paths toward maladjustment: Targets for intervention. Clinical Psychology Review, 12, 795-817.

Maker, A. H., Kemmelmeier, M., \& Peterson, C. (2001). Child sexual abuse, peer sexual abuse, and sexual assault in adulthood: A multi-risk model of revictimization. Journal of Traumatic Stress, 14, 351-368.

Nadelson, C., Notman, M., Jackson H., \& Gornick, J. (1982). A follow-up study of rape victims. American Journal of Psychiatry, 139, 1266-1270.

Paolucci, E., Genuis, M. L., \& Violato, C. (2001). A meta-analysis of the published research on the effects of child sexual abuse. The Journal of Psychology, 135, 17-36.

Patton, J. H., Stanford, M. S., \& Barratt, E. S. (1995). Factor structure of the Barratt Impulsiveness Scale. Journal of Clinical Psychology, 51, 768-774.

Piaget, J. (1976). The child and reality (A. Rosin, Trans.). Oxford, UK: Penguin.

Ryan, S. W., Rodriguez, N., Rowan A., \& Foy, D. W. (1992, August). Psychometric analysis of the Sexual Abuse Exposure Questionnaire (SAEQ). In Proceedings of the $100^{\text {th }}$ annual convention of the American Psychological Association, Washington, DC.

Schechter, J. O., Schwartz, H. P., \& Greenfield, D. G. (1987). Sexual assault and anorexia nervosa. International Journal of Eating Disorders, 6, 313316.

Smolak, L., \& Murnen, S. K. (2002). A meta-analytic examination of the relationship between child sexual abuse and eating disorders. International Journal of Eating Disorders, 31, 136-150.

Steel, J., Sanna, L., Hammond, B., Whipple, J., \& Cross, H. (2004). Psychological sequelae of childhood sexual abuse: Abuse-related characteristics, coping strategies, and attributional style. Child Abuse and Neglect, 28, 785-801.

Tanofsky, M. B., Wilfley, D. E., Spurrell, E. B., \& Welch, R. (1997). Comparison of men and women with binge eating disorder. International Journal of Eating Disorders, 21, 49-54.

Van der Kolk, B. A., Perry, J. C., \& Herman, J. L. (1991). Childhood origins of self-destructive behavior. American Journal of Psychiatry, 148, 16651671.

Veronen, L., \& Kilpatrick, D. (1983). Stress management for rape victims. New York: Plenum.

Waller, G. (1991). Sexual abuse as a factor in eating disorders. British Journal of Psychiatry, 159, 664-671.

Whiteside, S. P., \& Lynam, D. R. (2001). The five-factor model and impulsivity: Using a structural model of personality to understand impulsivity. Personality and Individual Differences, 30, 669-689. 


\section{CONLEY AND GARZA}

Wiederman, M. W. (1997). The truth must be in here somewhere: Examining the gender discrepancy in self-reported lifetime number of sex partners. Journal of Sex Research, 34, 375-386.

Wolfe, D. A., \& McGee, R. (1994). Dimensions of child maltreatment and their relationship to adolescent adjustment. Development and Psychopathology, 6, 165-181.

Wonderlich, S. A., Crosby, R. D., Mitchell, J. E., Thompson, K., Redlin, J., Demith, G., et al. (2001). Eating disturbance and sexual trauma in childhood and adulthood. International Journal of Eating Disorders, 30, 401-412. 